\title{
The Cultivation of the Spirit of China for College Students in the Internet Plus Era
}

\author{
Zhimei Zhang \\ Wuhan Textile University, Wuhan City, Hubei Province, 4300733, China
}

Keywords: Internet plus; college students; China spirit; cultivation path

\begin{abstract}
The spirit of China is a powerful spiritual force to promote the success of socialism with Chinese characteristics and a concentrated embodiment of socialist ideology. Influenced by the Internet deeply, contemporary college students' thinking consciousness is very active. As builders and successors of socialism have Chinese characteristics, it is of great practical significance to strengthen Chinese spiritual education. The arrival of the Internet Plus has enriched people's daily life, changed people's traditional ideas, and brought many opportunities for the cultivation of college students' Chinese spirit. Based on the author's learning and practical experience, this paper first analyzed the significance to strengthen the cultivation of college students' Chinese spirit, then studied the dilemma to cultivate Chinese spirit of college students in the Internet Plus era, and finally, put forward the methods to cultivate Chinese spirit of college students in the Internet Plus era.
\end{abstract}

\section{Introduction}

Contemporary college students should have a strong sense of Chinese spirit, inherit our excellent history and culture, and carry forward the Chinese spirit with their own practical actions to fully reflect the positive and vigorous spirit of college students. As an important part of ideological construction in our country, ideological and political education for college students plays an irreplaceable role in training qualified constructors and reliable successors of socialism. In the Internet Plus, ideological and political education should be based on the new changes of the times, new development of national conditions and new requirements of governance, grasp the pulse of the times, and vigorously guide college students to take on the historical responsibility and the mission of the times.

\section{The Significance to Strengthen the Cultivation of Chinese Spirit of College Students}

\subsection{It is necessary to further strengthen the cultivation of Chinese spirit of college students in} the new period

Only if the Chinese spirit is widely recognized, can it really provide strong spiritual power and intellectual support for Chinese Dream in practice. As a knowledge-intensive and ideological active group, college students are regarded as the backbone of the country in the future, shouldering the important task of national rejuvenation. Their recognition for Chinese spirit has a profound influence on the development direction and process of socialism with Chinese characteristics. At present, social transformation is accelerating, and the impact of foreign ideological trends is intensifying. With the development of the network, some social contradictions are more easily spread. The phenomenon that some students are dissatisfied with the social reality and are opposed to the mainstream consciousness seriously affects the cognition and recognition of the Chinese spirit and the motive force of practicing the Chinese spirit. To solve these problems, it is necessary to combine Chinese spirit with college students' study, life, professional development, ideals and beliefs in order to further enrich and strengthen the cultivation of contemporary college students' Chinese spirit. 


\subsection{It can guide the value orientation of College students with Chinese Spirit}

Xi Jinping said in a discussion with young college students: "Every era has its own spirit, and every era has its own values". The Chinese spirit is the common spirit which is gradually formed, consolidated, developed and sublimated in the development course of the Chinese nation, and is the spiritual link and inexhaustible motive force to realize the great rejuvenation of the Chinese nation. Guiding the development of College Students' value orientation with Chinese spirit is not only related to what kind of college students we want to train in Ideological and political work, but also the key to our university's ideological and political work to cultivate college students.

\subsection{It can promote the ideological realm of College students with Chinese Spirit}

At this stage, the national spirit with patriotism and the Spirit of the Times with Reform and Innovation have endowed the contemporary college students with a new connotation of ideological and political education. On one hand, the national spirit with patriotism and the Spirit of the Times with Reform and Innovation has become an important part for the cultivation of the Chinese spirit of college students, and has given a new connotation of the times to college students since the May 4th Movement. On the other hand, by combining the theory of Chinese spirit with the law of college students' growth, college students can feel the value of Chinese spirit, which is necessary to encourage college students to consciously integrate their individual ideals into the cause of the country and nation.

\section{The Predicament to cultivate the Chinese Spirit of College Students in Internet Plus Era}

\subsection{College students' values have changed}

Contemporary college students have a strong interest in trendy things and are easily receptive to new ideas, which will have an impact on their thinking consciousness to some extent. Especially in the current Internet era, the characteristics of college students will be displayed more vividly. The students' values for adults are still relatively vague, and they do not have enough right and rational judgment and analysis ability to treat things. The complicated network information bends the ideological consciousness formed by the college students in the past to varying degrees, and the existing national structure in the spirit of college students is divided into pieces and pieces, which has seriously affected college students' understanding for national spirit, so, there is no clear way to choose facing difficulties, and the values of the national spirit will be uncertain, and it will bring great impact on the future development of life.

\subsection{International culture has brought great impact}

In the past stages of learning, all the ways of knowledge sources are fixed and have no other influence on the outside forces. But in the Internet Plus era, the number of channels to receive information has increased, and the forms of information content have become more numerous. International culture also poured into the minds of college students like a huge wave. In the online world, without too many rules and sound legal system, it is an open platform for the whole world. As a result of such compatibility, many international cultures have vigorously promoted the outstanding attributes of their own culture, described the beautiful and peaceful life of their people, and demonstrated the democratic humanization of their national policies. This kind of information may weaken the national consciousness of the netizen, thus college students may produce a blind belief and yearning for it.

\subsection{Lack of spiritual education in China}

The elements of market economy, the category of elements, the form of employment and the division of interests have undergone subversive changes. All kinds of unfavorable elements enter the market economy, and the material thought of these elements is too heavy, which leads many bad phenomena, such as comparison psychology, vicious competition and getting without any labor. Lack of trust between people, lack of social responsibility, indomitable spirit of struggle gradually 
disappear. School related education work is not in place, and educators have not deeply understood the spirit of China, nor have they integrated the cultivation of this spirit into teaching. There are serious deficiencies in teaching content and teaching methods. If the technology advantage of Internet age is not applied to education, the effect of cultivating Chinese spirit of college students will not be ideal.

\section{The Path to Cultivate Chinese Spirit of College Students in Internet Plus Era}

\subsection{To build a strong cultivation atmosphere around the core values of socialism}

College students' group thoughts are active, and they are often sensitive and confused in the face of realistic contradictions. Their ideological struggle is fierce, and there are differences between spiritual cognition and practical actions. The socialist values advocate the value pursuit of socialist China from three aspects. It not only adheres to and innovates the Marxist value theory, inherits the essence of traditional Chinese spirit, but also reflects the common interest of the modern value concept. It points out the direction for the contemporary forging of the spiritual self of the Chinese nation. By leading the social and cultural life, the socialist core values can create a good social atmosphere, gather social consensus, and effectively assist college students to combine the knowledge and practice of the Chinese spirit at the social level. So that, young students have unswerving confidence in the Chinese spirit and practice it confidently and calmly.

\subsection{To strengthen theoretical research and perfect the theoretical system of Chinese spiritual cultivation}

The premise of identification and practice is rational and correct cognition. Therefore, it is necessary to further strengthen the theoretical research on the Chinese spirit and form a systematic and complete theoretical system. It is necessary to closely combine the theoretical development of Chinese spiritual cultivation of college students with the law of college students' growth so as to further enhance the pertinence and effectiveness of cultivation. First, it needs to further strengthen the theoretical development of the Chinese spirit, social realization ways, mechanisms and characteristics of the study, to enhance the persuasion and influence of theoretical guidance and practice; Second, it is necessary to further study the manifestation and development characteristics of different social groups, such as different strata, different industries, different ages and so on, in order to explore the practical path from theory to practice; Third, we should strengthen the research on the measurement index system of Chinese spiritual education and put it into the all-round growth practice of college students' moral, intellectual, physical and other aspects, so as to promote the integration of knowledge and practice.

\subsection{To strengthen educational innovation and enrich the Mode of Chinese Spirit cultivation}

There is no contradiction between strict cultivation and innovation for Chinese spiritual education of college students. We should not ignore the strict requirements for the cultivation of Chinese spirit for the sake of formal innovation, nor should we fall into the traditional mode of single examination-oriented education because of strict cultivation requirements. First, we should strengthen the research on the law of college students' growth, closely combine the cultivation of Chinese spirit with the law of college students' growth, act according to the law, and achieve twice the result with half the effort. Second, it is necessary to further strengthen the Chinese spiritual education of college students, strengthen the special topic study of Chinese spirit in the course of ideological and political theory teaching, carry out special teaching activities, and create a strong atmosphere of Chinese spiritual theory research and propaganda through various channels. Third, we should actively innovate the methods and forms of Chinese spiritual education for college students, draw lessons from foreign ideological propaganda forms, attach importance to new media propaganda, such as network, film and television. 


\subsection{To promote the cooperation between higher education and social education and to improve the cultivation effect}

On the basis of further study on the law of college students' cognition of Chinese spirit, we should grasp the different functions of different cognitive approaches. College students' cognitive approaches to Chinese spirit are diverse, and different cognitive pathways have different functions, and there is a systematic and synergistic relationship between them. First, to scientifically position the relationship between college cultivation and social education. Social and political propaganda, education and new media aim at enhancing the breadth of cognition and creating a strong atmosphere. Second, to give full play to the role of colleges and universities as the main position in promoting and educating the Chinese spirit of college students, to further strengthen the theoretical integration of the Chinese spirit and the innovation of the practical way. Third, we should carry out the Chinese spiritual and social practice of college students, give full play to their subjectivity, and cultivate their sense of ownership and ability to practice. Fourth, it is necessary to strengthen the summary, refinement and promotion of the ways and forms for Chinese spiritual education and publicity, to do a good job in publicizing and strengthening the guidance of China's spiritual advanced deeds, to formulate standards for the implementation of the Chinese spirit on campus, and to promote good campus culture and social atmosphere.

\section{References}

[1] Chen Xiaofang. Study on the cultivation path of Chinese Spirit for College students in the era of Internet[J]. Journal of Heihe University, ,2017, (11): 52-53.

[2] Li Yi. The present situation and Strategy of College students' spiritual cultivation in China[J]. Journal of College counselors, 2017, (03): 14-17.

[3] He Bing, Zhou Changmei. The realization of Contemporary College students' recognition of Chinese spiritual value[J]. Theoretic Observation, 2016, (10): 36-37.

[4] Li Dingqing, Liu Lei. Promoting the Chinese Spirit in Colleges and Universities to promote the realization of Chinese Dream[J]. Study on ideological Education, 2014, (10): 76-80.

Song Yan. Enhancement of Chinese spiritual Education for College students[J]. Journal of Ideological and theoretical education, 2014, (07): 87-90.

[6] Zhou Yamei. Practicing "Chinese Spirit": the cornerstone of responsibility education for post-90s college students[J]. Vocational education newsletter, 2014, (08): 72-73.

[7] Qian Shengjun, Xu Juan. Discussion on the cultivation path of higher Vocational College students' Chinese Spirit[J]. Journal of Hubei University of Economics, 2014, (03): 137-138. 